\title{
Production and characterisation of a recombinant scFv reactive with human gastrointestinal carcinomas
}

\author{
D-J Kim ',3, J-H Chung',3, Y-S Ryu', J-H Rhim', C-W Kim², Y Suh' and H-K Chung*,' \\ 'Department of Biochemistry and Molecular Biology, Cancer Research Institute, Seoul National University College of Medicine, Seoul, II 0-799, Korea; \\ ${ }^{2}$ Department of Pathology, Cancer Research Institute, Seoul National University College of Medicine, Seoul, II 0-799, Korea
}

\begin{abstract}
SCI42-reactive antigen are highly glycosylated glycoproteins expressed on tissues of gastric and colon cancers but not on normal tissues. Murine $\mathrm{SCl} 42$ antibody specific for the $\mathrm{SCl} 42$-reactive antigen has been produced by immunisation with SNUI6 stomach cancer cells. However, SCI 42 antibody has several potential problems such as high immunogenicity and poor tumour penetration owing to their large size. To improve tumour penetration potential in vivo, recombinant single-chain fragments have been produced using the original hybridoma cells as a source of variable heavy- and variable light-chainencoding antibody genes. The use of the polymerase chain reaction, expression cloning technology and gene expression systems in $\mathrm{E}$. coli has led to the production of $\mathrm{SCl} 42$ single-chain fragments, which was similar in activity to the $\mathrm{SCI} 42$ parent antibody confirmed by immunohistochemistry. Analysis by DNA sequencing, SDS-PAGE and Western blotting has demonstrated the integrity of the single-chain fragments. Competitive ELISA showed that SCI42 single-chain fragments originated from parent $\mathrm{SCl} 42$ antibody. BIAcore biosensor binding experiments showed that the $\mathrm{SCl} 42$ single-chain fragments had an ideal dissociation rate constant as a tumour imaging reagent. These results illustrate the potential application of these novel products as an immunodiagnostic and further immunotherapeutic reagent.
\end{abstract}

British Journal of Cancer (2002) 87, 405 -4I3. doi:10.1038/sj.bjc.6600365 www.bjcancer.com

(c) 2002 Cancer Research UK

Keywords: SCI42-reactive antigen; SCI 42 antibody; SCI 42 scFv; expression cloning

Mucins are high-molecular-weight glycoproteins composed by a carbohydrate moiety (mainly O-glycans) that represents $50-80 \%$ of their total mass and peptide core; also called apomucin, it is rich in Thr and Ser (Verma and Davidson, 1994). A variety of alterations of mucins have been described in metaplastic and malignant disease of the stomach (Correa, 1988). To detect those cancer associated alterations of gastric mucin, a number of monoclonal antibodies (mAbs) were developed. Although their specificity for cancer was limited compared with that of genetic markers such as p53, APC, c-met, $\mathrm{k}$-sam and c-erbB-2, immunohistological detection of antigen is much easier than molecular biological analysis of those gene abnormalities, and this is of practical importance.

In the previous study, we developed monoclonal antibodies elicited to the human stomach carcinoma cell line SNU16 to detect useful markers for gastric cancer. One of these monoclonal antibodies, SC142, detects an antigen present on adenocarcinoma cells of stomach. Preliminary studies on the molecular properties of the SC142-reactive antigen suggest that the epitope is sensitive to $\mathrm{O}$ glycanase and is expressed on a large, heavily glycosylated molecule indicating that the antigen is probably mucin (Hong et al, 2001).

In immunohistochemical studies, SC142-reactive antigen was not detected in normal gastrointestinal epithelium, whereas it was highly expressed in $78 \%$ of gastric cancers (29 out of 37) and $87 \%$ of colon cancers (27 out of 31 ) indicating that SC142 antibody can be a valuable tool to detect gastrointestinal cancers.

\footnotetext{
*Correspondence: H-K Chung; E-mail: address: hkchung@snu.ac.kr

${ }^{3}$ These authors contributed equally to this work

Received 27 December 200 I; revised 5 April 2002; accepted II April 2002
}

However, the use of whole antibody for in vivo imaging of cancer targets may have limitations due to their large molecular weight, with subsequent slow tumour uptake and long serum half-life (Power et al, 2001). Recombinant single chain variable fragments (scFvs), in which the two variable domains are covalently joined via a flexible peptide linker have overcome many of these problems. ScFvs usually show the same binding specificity and affinity as the monomeric form of the parent antibody (Bedzyk et al, 1990; Pantoliano et al, 1991) and may penetrate tumours more rapidly and evenly due to their relatively small size ( $M_{r} 27000$ vs $M_{r} 50000$ to 900000 for other immunoglobulin forms). The present investigation was initiated to produce derivatives of SC142 antibody that would improve tumour penetration potential in vivo. Here, we describe the production of a recombinant antibody fragment based on the variable region of the SC142 monoclonal antibody using expression cloning without antigen. Detailed analyses of the scFv confirm that its antigen recognition characteristics are similar to those of the parent antibody so that further diagnostic and therapeutic applications may be considered.

\section{MATERIALS AND METHODS}

\section{RNA extraction}

SC142 hybridoma cells $\left(1 \times 10^{7}\right)$ were harvested by centrifugation ( $1000 \mathrm{~g}$ for $5 \mathrm{~min}$ ), the supernatant removed by gentle aspiration, and the cellular pellet was vortexed briefly. Total RNA was extracted from the pellet using an Ultraspec RNA kit I (Biotecx, South Loop East, Houston). The RNA extract was then dissolved in $100 \mu \mathrm{l}$ of sterile water, quantified, and assessed for purity by 
absorbance determination at 280 and $260 \mathrm{~nm}$ (Sambrook et al, 1989). Samples were stored at $-70^{\circ} \mathrm{C}$.

\section{ScFv assembly}

Hybridoma total RNA served as the template for constructing SC142 scFv using the Recombinant Phage Antibody System (RPAS; Pharmacia, Uppsala, Sweden); incorporating many of the features described by McCafferty et al (1990) and Winter and Milstein (1991). Isolated, agarose gel-purified VH- and VL-encoding DNA were subsequently spliced together by PCR using primers designed to introduce a linking sequence between the two gene segments and specific restriction sites at both $5^{\prime}$ (SfiI) and $3^{\prime}$ (NotI) ends of the spliced sequence. Restriction digestion with SfiI and NotI endonucleases, and agarose gel purification of the digested linked product, preceded ligation of this DNA into the SfiI- and NotIdigested pRSET-Angiogenin SfiI/NotI vector (Figure 1). This vector was constructed from the pRSET SfiI/NotI vector (Yi et al, 1999) by PCR. The PCR protocol used the forward primer 5'-GTTATCCT GGCT GCCGCCTCCACCAGAGCCACCTCCGCCCGATCCGCCACCGCCTGCGGCCGCCCG-3' and the back primer $5^{\prime}$ CGTCCGTAAGCTTGATCCGGCTGCTAACAAAGCC-3' for 30 cycles of $1 \mathrm{~min}$ at $95^{\circ} \mathrm{C}, 2 \mathrm{~min}$ at $55^{\circ} \mathrm{C}$, and $1 \mathrm{~min}$ at $72^{\circ} \mathrm{C}$. After

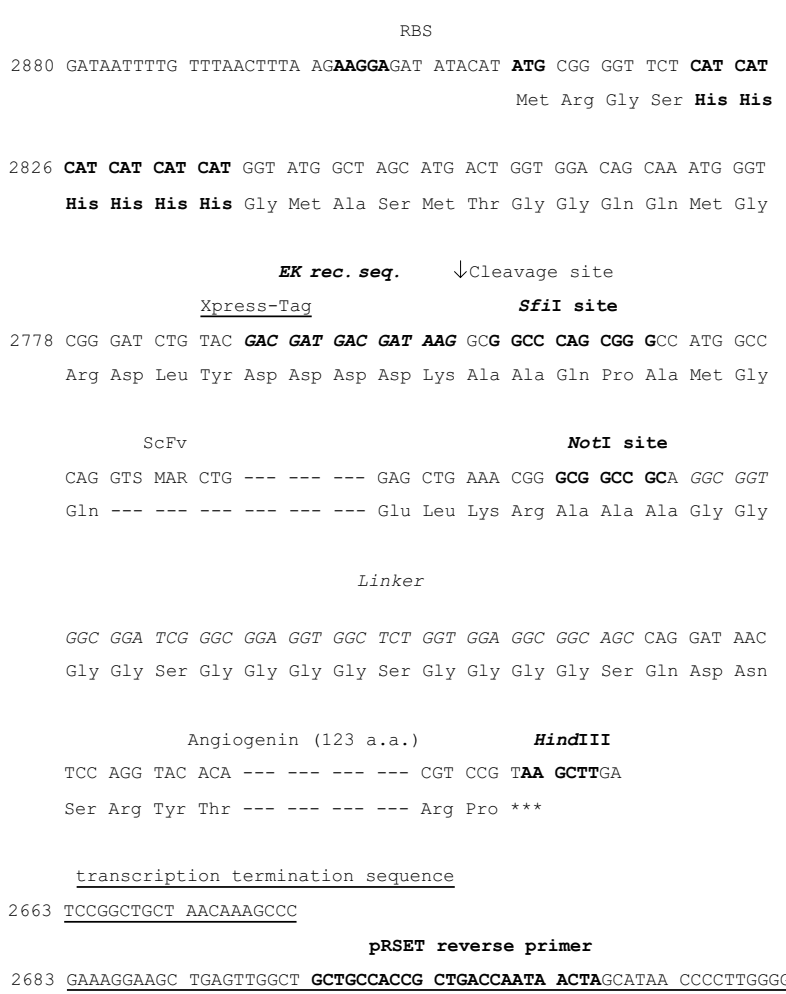

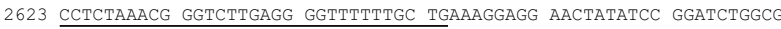

2563 TAATAGCGAA GAGGCCCGCA CCGATCGCCC TTCCCAACAG TTGCGCA -...............-

Figure I Relevant parts of the nucleotide and amino acid sequences of the SCI 42 scFv unit in PRSET-Angiogenin Sfil/Notl vector. The PRSET Sfill Notl vector (Yi et al, 1999) was amplified with the primers as described in Materials and Methods. The vector was modified to include a Hindlll site and angiogenin site after Notl site. The HIS-tag and Xpress-tag upstream from the enterokinase cleavage site can be removed by enterokinase treatment. The numbers in the left column indicate the nucleotide numbers of PRSET B (Invitrogen).
$1.0 \%$ agarose gel electrophoresis of the PCR products, the correctly sized band of $3.0 \mathrm{~kb}$ was excised. The DNA was purified using the Qiaex II gel extraction kit (Qiagen, Stanford Valencia, CA, USA). Human angiogenin was linked to equal moles of the vector by overlap extension PCR with the forward primer 5'-TCAAGCTTACGGACG- $3^{\prime}$ and the back primer $5^{\prime}$-TAAGCTTGATCCGGCTGCTAACAAAGCC- $3^{\prime}$. PCR reagents were subjected to 30 cycles of $1 \mathrm{~min}$ at $95^{\circ} \mathrm{C}, 2 \mathrm{~min}$ at $55^{\circ} \mathrm{C}$, and $1 \mathrm{~min}$ at $72^{\circ} \mathrm{C}$. After $1.0 \%$ agarose gel electrophoresis of the PCR products, the correctly sized band of $3.3 \mathrm{~kb}$ was excised. This vector was digested with HindIII restriction enzyme and ligated using a ligation kit (Gibco-BRL, Grand Island, NY, USA). This vector was amplified in heat competent E. coli XL-1 blue cells (Stratagene, La Jolla, CA, USA) and then extracted with a QIAprep spin miniprep kit (Qiagen). This vector was used to transform competent BL21 E. coli cells (Novagen, Madison, WI, USA) using a heat shock $\left(42^{\circ} \mathrm{C}\right)$ transformation method. Ten individual colonies were selected from each transformation. Transformed BL21 E. coli were then subjected to culture protocol, producing a recombinant scFv of SC142 encoding $\mathrm{VH}-$ and VL-linked genes.

\section{Primer design}

The primers used in the scFv assembly were provided in the RPAS mouse scFv module. Primers used in sequencing reactions and in PCR analyses were T7 primers.

\section{Analysis of scFv clones by sodium dodecyl sulphate (SDS) polyacrylamide gel electrophoresis (SDS - PAGE) and Western blotting}

Induction of $\mathrm{scFv}$ expression was achieved using the LacZ promoter of the pRSET-Angiogenin SfiI/NotI vector by the addition of isopropyl beta-D-thiogalactopyranoside (IPTG) substrate into LB medium supplemented with $100 \mu \mathrm{g} \mathrm{ml}^{-1}$ ampicillin (Sambrook et al, 1989). A total of $10 \mathrm{ml}$ of substrate was added. Ten clones were then chosen and subjected to scFv expression for functional immunoglobulin gene analysis before SDS-PAGE and Western blot analyses were performed.

The cells harbouring expressed scFv were solubilised with SDSloading buffer (bromophenol blue $\left(0.05 \% \mathrm{w} \mathrm{v}^{-1}\right)$, glycerol $(25 \%)$ ). Proteins were separated by proper concentration of SDS-PAGE and stained with Coomassie brilliant blue R (Sigma, St. Louis, MO, USA) or transferred to nitrocellulose membranes (Schleicher \& Schuell, Keene, NH, USA). Membranes were incubated for $1 \mathrm{~h}$ with the blocking buffer ( $5 \%$ non-fat milk $\left(\mathrm{w} \mathrm{v}^{-1}\right)$ in phosphate-buffered saline (PBS, $\mathrm{pH} 7.4)$ containing $0.2 \%\left(\mathrm{w} \mathrm{v}^{-1}\right)$ Tween 20 (PBS/Tween) for Western blot analysis. Anti-Xpress Abs were used at a 1:1000 dilution, and secondary horseradish peroxidase-conjugated Abs (Pierce, Rockford, IL, USA) at a $1: 10000$ dilution.

The SC142 scFv gene fragment, a fusion protein of predicted size in SDS-PAGE and Western blot analyses and found to be positive in ELISA and confirmed by DNA sequencing, was subcloned into pRSET SfiI/NotI vector (Yi et al, 1999) and transformed into E. coli BL21 (DE3) cells for SC142 scFv purification.

\section{DNA sequencing analysis}

The clone containing SC142-encoding DNA, and in which expression of the $\mathrm{scFv}$ was demonstrated using Western blotting, was further analysed using manual Sanger dideoxy DNA sequencing.

\section{Production of SC142 scFv}

Expression of the SC142 scFv fragment was induced via the addition of $1 \mathrm{mM}$ IPTG followed by incubation for $3 \mathrm{~h}$ at $37^{\circ} \mathrm{C}$. From 
$200 \mathrm{ml}$ culture, the cells were harvested, washed twice with PBS and the final cell pellet was stored at $-20^{\circ} \mathrm{C}$ prior to $\mathrm{scFv}$ purification.

\section{Purification of SC142 scFv}

To purify $\mathrm{scFv}$, the washed cell pellet was resuspended in PPET buffer containing $2 \mathrm{mM}$ EDTA, 2\% Triton X-100, and $1 \mathrm{mM}$ PMSF in PBS, ultrasonicated and centrifuged at $24300 \mathrm{~g}$ for $30 \mathrm{~min}$. The supernatant was removed and the pellet was resuspended in fresh PPET buffer. This step was repeated four times. The final supernatant was discarded and the inclusion body pellet was subjected to SDS-PAGE, Coomassie brilliant blue staining and Western blotting for check of purity.

\section{Refolding of SC142 scFv}

The inclusion body pellet was solubilised in $50 \mathrm{~mm}$ Tris- $\mathrm{HCl}$ $(\mathrm{pH} 8.0)$ containing $6 \mathrm{M}$ guanidine- $\mathrm{HCl}(\mathrm{GuHCl}), 200 \mathrm{mM} \mathrm{NaCl}$ and $10 \mathrm{~mm} 2$-mercaptoethanol $\left(\beta\right.$-ME) overnight at $4{ }^{\circ} \mathrm{C}$. The solubilised precipitant was subsequently centrifuged at 12000 r.p.m. and the supernatant was subjected to the refolding step. Refolding of $\mathrm{scFv}$ was performed according to Tsumoto et al. (1998).

\section{Size-exclusion FPLC chromatography and molecular mass determination}

Refolded scFv was analysed by size-exclusion chromatography on a calibrated Bio-Prep SE-100/17 column (Bio-Rad Laboratories, Sydney, Australia) at a flow rate of $0.5 \mathrm{ml} \mathrm{min}^{-1}$ in $50 \mathrm{~mm}$ Tris ( $\mathrm{pH}$ 8.0). The column was calibrated using standard molecular mass markers, containing thyroglobulin, IgG, ovalbumin, myoglobin, vitamin $\mathrm{B}_{12}$ (Bio-Rad Laboratories, Sydney, Australia).

\section{Purification of SC142-reactive antigen}

Culture supernatants and membrane fractions of SNU16 cells were used for cesium chloride density gradient ultracentrifugation performed using the method described by Creeth and Denborough (1970). The densities of every fraction was determined by weighing $200 \mu \mathrm{l}$ in a calibrated micropipette. In order to identify the fractions containing the SC142-reactive antigen, duplicates of $100 \mu \mathrm{l}$ from each fraction were then applied to enzyme-linked immunosorbent assay described by Ching and Rhodes (1990). CsCl was removed by dialysis against water, and assays of each fraction's protein concentration was performed.

\section{Biotinylation of SC142 scFv}

Recombinant SC142 scFv was coupled with biotin at concentrations of $100 \mu \mathrm{g} \mathrm{ml}^{-1}$ in PBS by the $\mathrm{N}$-hydroxysuccinimide (NHS) esters coupling procedure described by the manufacturer (Pierce). Similarly, the degree of biotin incorporation was determined by the HABA method recommended by the manufacturer.

\section{Immunoreactivity by enzyme-linked immunosorbent assay (ELISA) and competitive ELISA}

Microtitre plates (96-well, flat bottomed, Nunc) were coated with purified SC142-reactive antigen $\left(5 \mu \mathrm{g} \mathrm{ml}^{-1}\right)$ for $16 \mathrm{~h}$ at $4^{\circ} \mathrm{C}$. The wells were washed four times with PBS/Tween, and the remaining non-specific sites were blocked by the addition of 3\% BSA for $1 \mathrm{~h}$. After four washes in PBS/Tween, $50 \mu \mathrm{l}$ recombinant SC142 scFv $\left(25 \mu \mathrm{g} \mathrm{ml}^{-1}\right)$ was added to each well and incubated for $8 \mathrm{~h}$. For the competition ELISA, $25 \mu \mathrm{l}$ of recombinant SC142 scFv $\left(50 \mu \mathrm{g} \mathrm{ml}^{-1}\right)$, and $25 \mu \mathrm{l}$ of SC142 monoclonal antibody $\left(50 \mu \mathrm{g} \mathrm{ml}^{-1}\right.$ ) in $3 \% \mathrm{BSA} / \mathrm{PBS}$, were added to each well and incubated for $8 \mathrm{~h}$. The control well was incubated with only the same amount of recombinant SC142 scFv. Another control well was incubated with only $50 \mu \mathrm{l}$ of SC142 monoclonal antibody and developed with goat anti-mouse IgGAM/horseradish peroxidase conjugate at $1: 1000$ in 3\% BSA/PBS. The plates were then washed ten times and $50 \mu \mathrm{l}$ of anti-Xpress antibody at $1: 1000$ in $3 \% \mathrm{BSA} /$ PBS was added, to each well, and incubated for $1 \mathrm{~h}$. The plates were washed ten times in PBS/Tween. And then $50 \mu \mathrm{l}$ of goat anti-mouse IgG/horseradish peroxidase conjugate at $1: 1000$ in $3 \%$ BSA/PBS was added, to each well, and incubated for $1 \mathrm{~h}$. After incubation the plates were washed 10 times in PBS/Tween. In addition to a solution of $0.1 \mathrm{M}$ citrate phosphate buffer $\mathrm{pH} 5.8$, with $33 \%\left(\mathrm{v} \mathrm{v}^{-1}\right) \mathrm{H}_{2} \mathrm{O}_{2}$ (Sigma) which was added at a concentration of $0.3 \mu \mathrm{l} \mathrm{ml} \mathrm{m}^{-1}, 2 \mathrm{mg} \mathrm{ml}{ }^{-1}$ of $o$-phenylenediamine (Sigma) was added to each of the wells at $100 \mu$ per well. Analysis of colour development was assessed over a 10 min period using an ELISA reader.

\section{Surface plasmon resonance studies}

The BIAcore biosensor (Pharmacia), which uses surface plasmon resonance detection and permits real-time kinetic analysis of two interacting species, was used to measure the binding kinetics of the SC142 antibody and scFv. Covalent immobilisation of SC142 antibody and recombinant SC142 scFv was performed via free amine groups using $\mathrm{N}$-hydroxysuccinimide/ $\mathrm{N}$-ethyl- $\mathrm{N}^{\prime}$ (dimethylaminopropyl) carbodiimide (NHS/EDC) coupling as described previously (Gruen et al, 1993). Immobilisation of SC142 monoclonal antibody was performed in $10 \mathrm{mM}$ sodium acetate, $\mathrm{pH} 5.0$, at a flow of $5 \mu \mathrm{l} \mathrm{min} \mathrm{min}^{-1}$ (6066 resonance units (RU) immobilised). Similarly, immobilisation of SC142 scFv was performed in $10 \mathrm{~mm}$ sodium acetate, $\mathrm{pH} 4.8$, with an initial

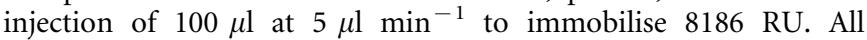
binding experiments were performed on an upgraded Pharmacia BIAcore 2000 in HBS buffer, pH 7.4 (10 mM HEPES, $150 \mathrm{~mm}$ $\mathrm{NaCl}, 3.4 \mathrm{~mm}$ EDTA) including $0.005 \%(\mathrm{v} \mathrm{v})$ of the nonionic detergent P20 (Pharmacia). The kinetic constants for dissociation $\left(K_{\mathrm{D}}\right)$ were evaluated using BIAevaluation 3.0 software (Pharmacia), from average $k_{a}$ (association rate) and $k_{d}$ (dissociation rate) kinetics.

\section{Immunohistochemistry}

Immunohistochemistry was performed using the method described by Denton et al. (1997). The biotin-labelled SC142 scFv was applied for $1 \mathrm{~h}$. Optimal antibody concentrations were determined by titration. To detect scFv binding, specimens were incubated for $1 \mathrm{~h}$ with streptavidin/horseradish peroxidase conjugate $(1: 50)$

\section{RESULTS}

\section{SC142 scFv assembly and expression}

Insertion of SC142 VH- and VL-specific DNA in the scFv assembly process was analysed by expression of the DNA from transformants of BL21 E. coli clones grown on ampicillin plates. These tests were performed using Coomassie blue staining and Western blot analysis with anti-Xpress antibody. The pRSETAngiogenin SfiI/NotI expression vector uses a reporter sequence known as the Xpress-tag to show the presence of scFv (Figure 1). A murine antibody recognising the Xpress-tag peptide sequence allows the presence of expressed $s c F v$ to be visualised on Western blots. The use of this reporter, plus analysis of the product size through SDS-PAGE, reveals the presence of intact recombinant scFv. Of 10 randomly selected clones, three 

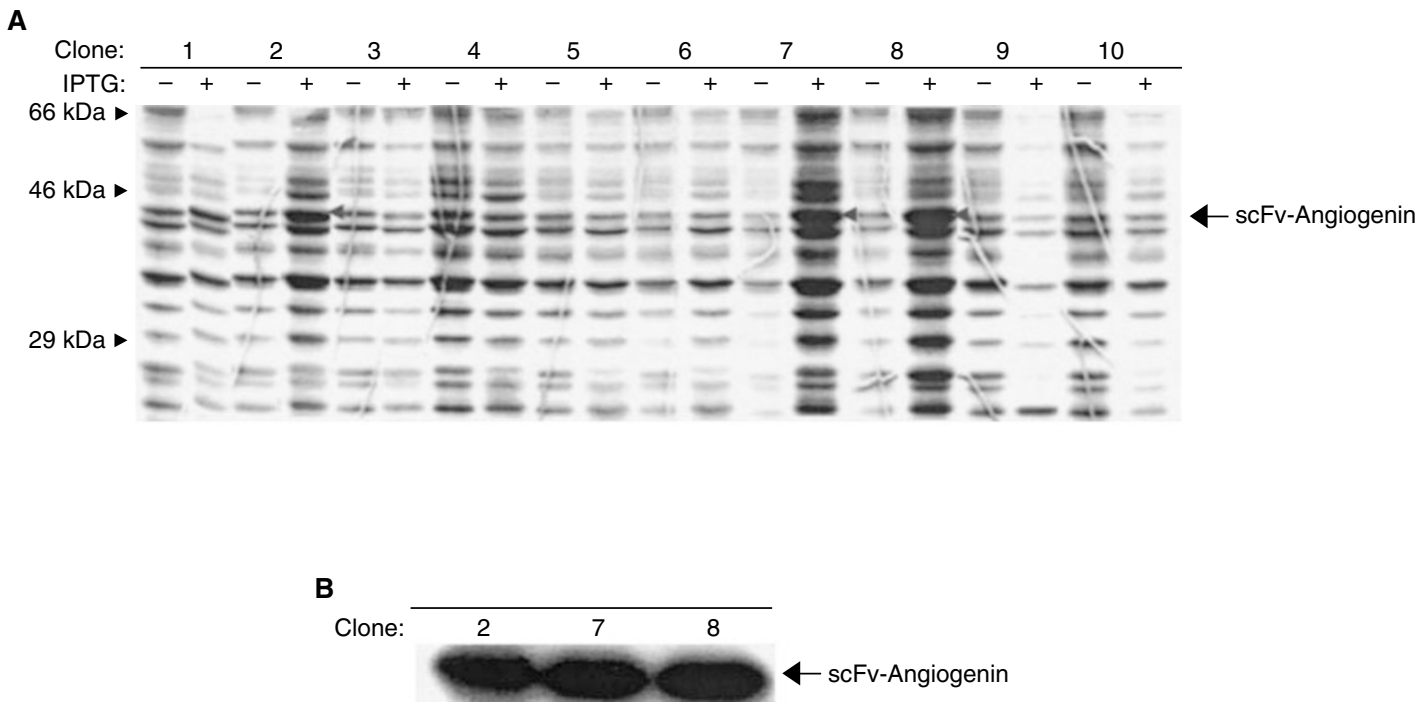

Figure 2 Screening of scFv by scFv expression. E. coli BL2I transformed cells containing expressed scFv were lysed and subjected to SDS - PAGE (I 2\%) and stained with Coomassie blue staining after separating proteins on reducing SDS-PAGE gels. (A) Protein expression pattern before and after IPTG induction. Left-oriented arrowheads indicate relatively highly expressed protein bands. (B) Western blot analysis of selected clones using anti-Xpress antibody.

Table I Deduced amino acid sequence of SCI $42 \mathrm{scFv}$. Underlined and italic residues indicate linker sequence. The VL domains are precisely fused to a sequence encoding the linker, which in turn are fused to $\mathrm{VH}$ domains

\begin{tabular}{|c|c|c|c|c|c|c|c|c|c|c|c|c|c|c|c|c|c|c|c|c|}
\hline \multicolumn{21}{|l|}{$\mathbf{V H} \rightarrow$} \\
\hline I & Gln & Val & Lys & Leu & Gln & Gln & Ser & Gly & Thr & Glu & Val & Val & Lys & Pro & Gly & Ala & Ser & Val & Lys & Leu \\
\hline 21 & Ser & Cys & Lys & Ala & Ser & Gly & Tyr & \|le & Phe & Thr & Ser & Tyr & Asp & $\| \mathrm{e}$ & Asp & Trp & Val & Arg & Gln & Thr \\
\hline 41 & Pro & Glu & Gln & Gly & Leu & Glu & Trp & lle & Gly & Trp & $\| \mathrm{e}$ & Phe & Pro & Gly & Glu & Gly & Ser & Thr & Glu & Tyr \\
\hline 61 & Asn & Glu & Lys & Phe & Lys & Gly & Arg & Ala & Thr & Leu & Ser & Val & Asp & Lys & Ser & Ser & Ser & Thr & Ala & Tyr \\
\hline 81 & Met & Glu & Leu & Thr & Arg & Leu & Thr & Ser & Glu & Asp & Ser & Ala & Val & Tyr & Phe & Cys & Ala & Arg & Gly & Asp \\
\hline 101 & Tyr & Tyr & Arg & Arg & Tyr & Phe & Asp & Leu & Trp & Gly & Gln & Gly & Thr & $\begin{array}{c}\text { Thr } \\
\mathbf{V L} \rightarrow\end{array}$ & Val & Thr & Val & Ser & Ser & Cys \\
\hline 121 & Gly & Gly & Gly & Ser & Gly & Gly & Gly & Gly & Pro & Gly & Gly & Gly & Gly & Ser & Asp & lle & Glu & Leu & Thr & Gln \\
\hline $14 \mid$ & Ser & Pro & Thr & Ile & Met & Ser & Ala & Ser & Pro & Gly & Glu & Arg & Val & Thr & Met & Thr & Cys & Ser & Ala & Ser \\
\hline 161 & Ser & Ser & \|le & Arg & Tyr & $\| \mathrm{e}$ & Tyr & Trp & Tyr & Gln & Gln & Lys & Pro & Gly & Ser & Ser & Pro & Arg & Leu & Leu \\
\hline 181 & $\| \mathrm{e}$ & Tyr & Asp & Thr & Ser & Asn & Val & Ala & Pro & Gly & Val & Pro & Phe & Arg & Phe & Ser & Gly & Ser & Gly & Ser \\
\hline 201 & Gly & Thr & Ser & Tyr & Ser & Leu & Thr & $\| \mathrm{e}$ & Asn & Arg & Met & Glu & Ala & Glu & Asp & Ala & Ala & Thr & Tyr & Tyr \\
\hline 221 & Cys & Leu & Glu & Trp & Ser & Gly & Tyr & Pro & Tyr & Thr & Phe & Gly & Gly & Gly & Thr & Lys & Leu & Glu & Leu & Lys \\
\hline
\end{tabular}

produced expression products of approximately $45 \mathrm{kDa}$ in length (Figure 2). The size of these products is consistent with the assembly of linked $\mathrm{VH}$ and VL into the vector containing human angiogenin. To verify whether choosing clones by product size was suitable for selecting clones with functional antibodies, we performed ELISA on the clones containing fragments of the correct size. The results of the ELISA demonstrated that all of the clones with correctly sized fragments were functional. All of the functional clones were further analysed by employing DNA sequencing techniques using the primers T7 to identify the exact DNA sequence of the inserted SC142-encoding region. DNA sequencing analysis of selected functional clones demonstrated that all of the functional clones were identical and that mutation of the linker sequence, in which Gly ${ }^{120}$ is changed to Cys and Ser ${ }^{129}$, has changed to Pro (Table 1). Although mutation of the linker sequence occurred, because binding activity of all the clones was not changed through ELISA, we analysed the characteristics of SC142 scFv further.

For this additional characterisation of SC142 scFv, we subcloned the $s c F v$ gene fragments into the pRSET Sfil/NotI vector, transformed it into E. coli BL21 cells, and produced SC142 scFv.
Preliminary studies were performed in which whole-cell extracts, periplasmic extracts, and supernatants from cultures of clones were tested for the presence of scFv by SDS-PAGE and Western blotting. All of the clones expressed insoluble recombinant $\mathrm{scFv}$ in sufficient quantities to be revealed in the inclusion bodies by Western blotting (data not shown). Inclusion bodies were solubilised and renatured as described in Materials and Methods. Appropriate fractions were further analysed by SDS-PAGE and Western blotting. Figure 3A (lane 2 in the left panel) depicts the purified protein as a single band of approximately $30 \mathrm{kDa}$ by SDS-PAGE. After Western blot analysis of the same sample, Figure 3A (lane 4 in the right panel) shows that this protein contains the Xpress-tag sequence and therefore identify it as SC142 scFv.

The monomeric state of SC142 scFv was analysed by gel filtration. Purified SC142 scFv contained predominantly a peak eluting with an apparent molecular mass of $\sim 30 \mathrm{kDa}$, consistent with a monomeric scFv with a calculated $M_{r}$ of 30256 (Figure $3 \mathrm{C})$. This result confirmed that the SC142 scFv with a 15 amino acid residue linker joining the $\mathrm{VH}$ and $\mathrm{VL}$ domains formed a stable scFv, not multimers. 
A

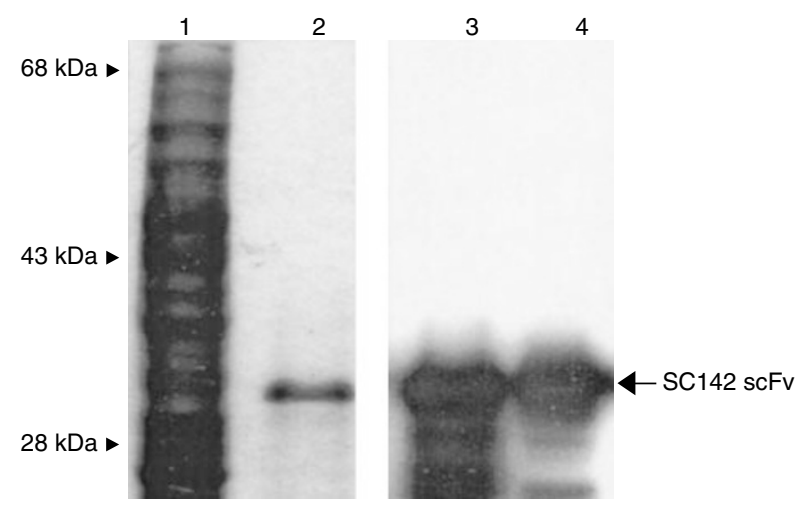

B

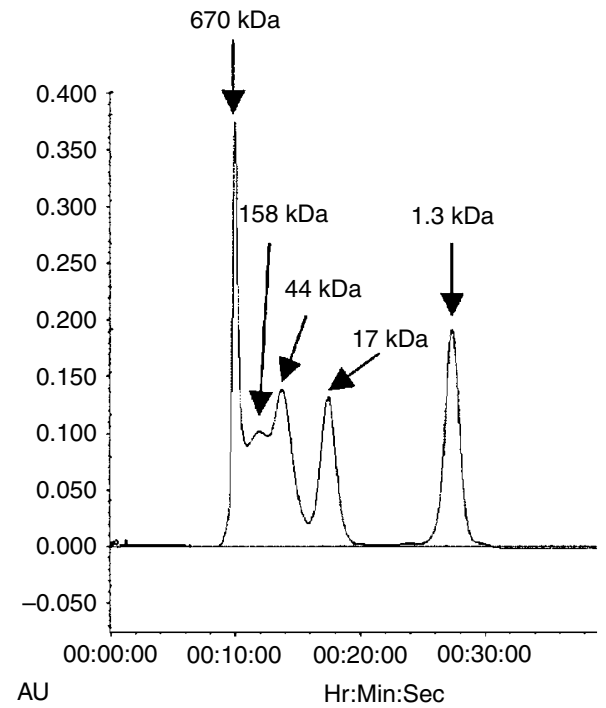

C

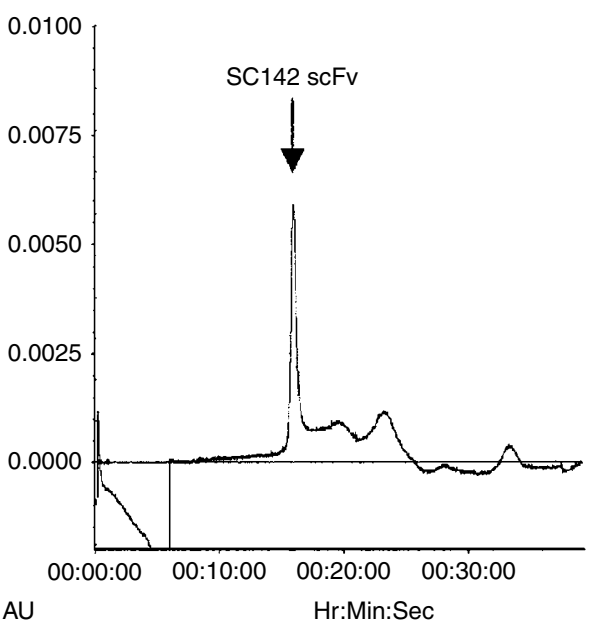

Figure 3 SDS - PAGE and Western blot analysis of purified SCI 42 scFv. Left panel of $(\mathbf{A})$ is Coomassie blue stained SDS-PAGE and right panel of (A) is Western blot analysis of E. coli BL2I (DE3) cells overproducing SCI 42 scFv probed with anti-Xpress antibody. Lanes I and 3 are whole cell lysate and lane 2 and 4 are purified SCI $42 \mathrm{scFv}$. (B) chromatogram of molecular standards; (C) chromatogram of the purified and refolded SCI42 scFv.

\section{Purification of SC142-reactive antigen}

To characterise recombinant SC142 scFv, we needed to purify the SC142-reactive antigen, a novel tumour-associated mucin. Given that immunoaffinity chromatography was an ineffective means of purifying the SC142-reactive antigen, alternative purification methods were sought. Typically non-glycosylated proteins and glycoproteins have densities ranging from 1.20 to $1.30 \mathrm{~g} \mathrm{ml}^{-1}$, whereas heavily glycosylated glycoproteins, such as mucin, have densities in excess of $1.40 \mathrm{~g} \mathrm{ml}^{-1}$ (Lan et al, 1985). The SC142reactive antigen is expressed in SNU16 cells, and also secreted into culture medium of SNU16 cells. When the culture supernatants or membrane fractions of SNU16 cells were subjected to cesium chloride density gradient centrifugation, a prominent peak of SC142 antibody binding glycoprotein sedimented with a density of more than $1.40 \mathrm{~g} \mathrm{ml}^{-1}$ as would be expected for a mucin (Figure 4). Table 2 summarises the purification of SC142-reactive antigen.

\section{Competitive ELISA}

To confirm whether SC142 scFv originates from parental SC142 antibody, we performed competitive ELISA. A checkerboard assay was used before competitive ELISA to optimise the concentrations of both SC142-reactive antigen and SC142 scFv. The coating concentration of SC142-reactive antigen was $5 \mu \mathrm{g}$ well $^{-1}$ and the concentration of SC142 scFv was $25 \mu \mathrm{g}$ well $^{-1}$ (data not shown). As the result of competitive ELISA, SC142 scFv binding was completely inhibited by the original SC142 antibody (Figure 5).

\section{BIAcore analysis}

Generally, scFvs have the same binding affinity as the monomeric form of the parent antibody, but this is not true in all cases. Although SC142 scFv originated from the SC142 antibody and demonstrated the same binding specificity as the SC142 antibody, its binding affinity could nonetheless differ from that of the SC142 antibody. BIAcore analysis was therefore used to determine an exact affinity constant for both SC142 scFv and the SC142 antibody (Figure 6, see Materials and Methods). SC142 scFv exhibited a relative $K_{\mathrm{D}}$ of $6.68 \times 10^{-7} \mathrm{M}$ (Table 3 ). This value compares favourably with affinity constants for the intact SC142 monoclonal antibody $\left(2.88 \times 10^{-8} \mathrm{M}\right)$.

\section{Immunohistochemistry>}

Immunohistochemical staining was used to test the ability of SC142 scFv to bind to tumour cells. It shows the ability of SC142 antibody (Figure 7B) and SC142 scFv (Figure 7D) to preferentially bind to stomach tumour tissue sections. The surface staining pattern is characteristic of the expression of SC142-reactive antigen. Some weak staining to the normal cells using the whole antibody is seen in Figure 7A but is not observed for the scFv (Figure 7C).

\section{DISCUSSION}

Four decades of research show that the immune response to tumour antigens and probably to other antigens, is diminished in patients with cancer. In addition a widely quoted article in this journal reported no evidence of immune response to 27 different spontaneous tumours in mice (Hewitt et al, 1976). Attempts for generating human antibodies against tumour antigen have been hampered by these reasons. Based on these facts, immune mice would be an alternative and attractive source to produce antibodies specific for tumour antigen. 


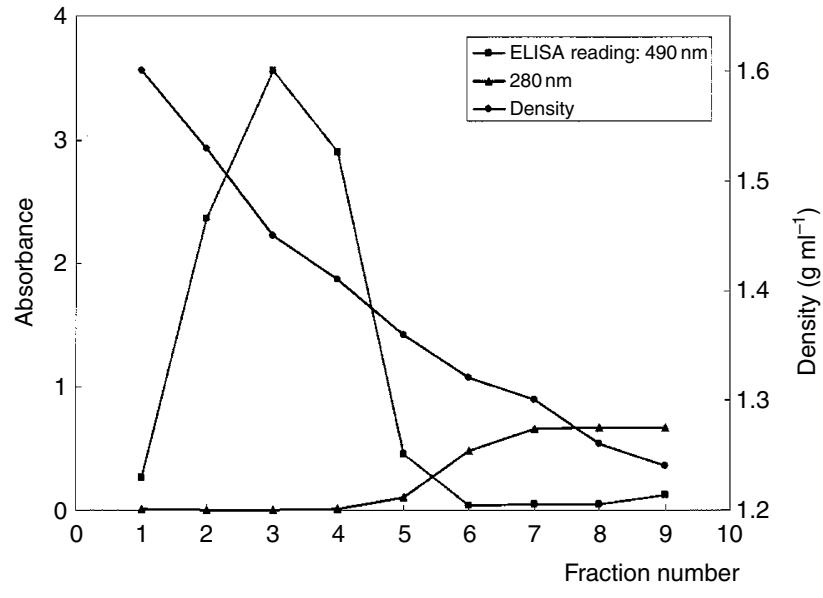

Figure 4 Purification of $\mathrm{SCl}$ 42-reactive antigen by $\mathrm{CsCl}$ density gradient centrifugation. Enzyme-linked SCI 42 antibody assay of the fractions were separated by cesium chloride density gradient ultracentrifugation showing a major peak with density $>1.40 \mathrm{~g} \mathrm{ml}^{-1}$.

Table 2 Purification of SCI42-reactive antigen

\begin{tabular}{lccccc}
\hline Step & $\begin{array}{c}\text { Protein } \\
(\mathbf{m g})^{\mathbf{a}}\end{array}$ & $\begin{array}{c}\text { Total } \\
\text { activity } \\
\text { (units) }^{\mathbf{b}}\end{array}$ & $\begin{array}{c}\text { Specific } \\
\text { activity } \\
\text { (units } \mathbf{~ m g}^{-\mathbf{1}} \text { ) }\end{array}$ & $\begin{array}{c}\text { Purification } \\
\text { (fold) }\end{array}$ & $\begin{array}{c}\text { Yield } \\
\text { (\%) }\end{array}$ \\
\hline $\begin{array}{l}\text { Starting material } \\
\begin{array}{l}\text { CsCl density gradient } \\
\text { ultracentrifugation }\end{array}\end{array}$ & 282.7 & 42022.2 & 148.6 & 1 & 100 \\
\hline
\end{tabular}

${ }^{a}$ Amounts of protein were determined at $280 \mathrm{~nm}$, and those were calculated by bovine serum albumin standard curve. ${ }^{b}$ One unit is defined as the increase of absorbance 0.0 l at $490 \mathrm{~nm}$ in ELISA reading.

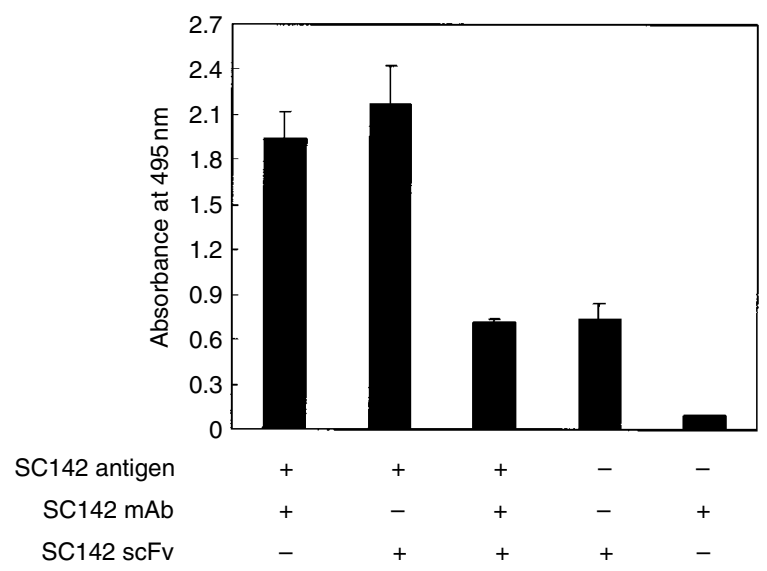

Figure $5 \mathrm{SCl} 42 \mathrm{scFv}$ binds specifically to $\mathrm{SCl} 42$-reactive antigen confirmed by competition of the SCI 42 scFv with SCI $42 \mathrm{mAb}$ to SCI42-reactive antigen. Bound scFv was detected with anti-Xpress antibody. The vertical bars are propotional to the absorbance obtained by ELISA, and bars represent the standard deviations.

Over the past years, we have generated antibodies specific for stomach cancer-associated antigen by immunisation with the
Table 3 Apparent kinetic rate constants and equilibrium binding constants for the interaction of SCl42-reactive antigen with immobilised SCI 42 antibody and SCI 42 scFv

\begin{tabular}{llcc}
\hline $\begin{array}{l}\text { Immobilised } \\
\text { ligand }^{\mathbf{a}}\end{array}$ & Analyte & $\begin{array}{c}\text { Apparent } \\
\boldsymbol{K}_{\boldsymbol{a}} \mathbf{( M}^{-\mathbf{1}} \mathbf{s}^{-\mathbf{1}} \mathbf{)}\end{array}$ & $\begin{array}{c}\text { Apparent } \\
\boldsymbol{K}_{\boldsymbol{d}}\left(\mathbf{s}^{-\mathbf{1}}\right)\end{array}$ \\
\hline $\mathrm{SCI} 42 \mathrm{mAb}$ & $\mathrm{SCI}$ 42-reactive antigen & $2.86 \times 10^{4}$ & $8.25 \times 10^{-4}$ \\
$\mathrm{SCI} 42 \mathrm{scFv}$ & $\mathrm{SCI} 42$-reactive antigen & $1.16 \times 10^{3}$ & $7.76 \times 10^{-4}$ \\
\hline
\end{tabular}

The rate constants were determined for the binding data (Figure 7) using global fitting for the data set as described in BIAevaluation 3.0 with the I: I Langmuir binding model.

SNU-16 stomach cancer cell line, and SC142 antibody is one of them (Hong et al, 2001). The SC142 monoclonal antibody, IgM, recognised O-glycan in a mucin-like glycoprotein. The SC142-reactive antigen was expressed mainly in gastrointestinal cancers, especially in colon and stomach cancers. Practically, all normal gastrointestinal tissues did not react with $\mathrm{SC1} 42$ antibody. However, SC142 antibody has high molecular weight thereby limiting their potential use for in vivo imaging applications. In order for whole antibodies against tumour to be used as diagnostic imaging reagents, they have been minimised to recombinant antibodies. Also, conversion of the hybridoma-produced antibody to a bacterially expressed fragment is a prerequisite of modelling and humanisation for a further therapeutic reagent (Hoogenboom et al, 1998).

The results presented here confirm the successful production of a recombinant single-chain antibody fragment $(\mathrm{scFv})$ retaining the capacity to bind to the SC142-reactive antigen. Assembly of scFv, using the antibody variable region genes and the fusion protein expression cloning system, produces a recombinant protein in which the structural features that define the high specificity of the parent antibody for its antigen are retained. Alterations in the sequence of SC142 scFv probably arose from unspecific priming under the amplification procedure. Although prolines in the linker regions of scFv may not be the most optimal amino acid residues for a flexible linker, they did not influence on function of the scFv.

The fusion protein expression cloning system was chosen because of two reasons. Firstly, it was difficult to purify SC142reactive antigen required for constructing a phage display library and producing scFvs. SC142-reactive antigen purification by immunoaffinity column chromatography was unsuccessful, since the SC142 antibody shows poor antigen binding when coupled to insoluble matrix. Therefore, we needed the system developing recombinant SC142 scFv without antigen. Secondly, only a few percentage of the clones produced antibodies in the expected size range in establishing antibody libraries from lymphocytes or hybridomas because there are aberrant immunoglobulin genes that carry the nonsense mutation in the mRNA pool of a lymphocyte which has one functional immunoglobulin gene. Therefore, we used the fusion protein expression cloning system to overcome aberrant mRNA contamination when cloning functional immunoglobulin RNA. The methodology we have selected here, based on fusion protein expression cloning, enabled us to distinguish functional immunoglobulin genes that produced protein products of predicted size from aberrant immunoglobulin genes.

BIAcore assays indicate recombinant SC142 $\mathrm{scFv}$ is high-affinity anticarbohydrate antibody. The reason that $k_{\text {on }}$ and $k_{\text {off }}$ of SC142 $\mathrm{scFv}$ are different from those of the original antibody may result from heterogeneity of functional light chain gene from single B lymphocytes (Jena et al, 2000). Therefore, binding affinity of SC142 scFv is slightly different from the original SC142 antibody. Also, BIAcore data is consistent with competition ELISA data because BIAcore assays show that on-rate of SC142 antibody is 
A

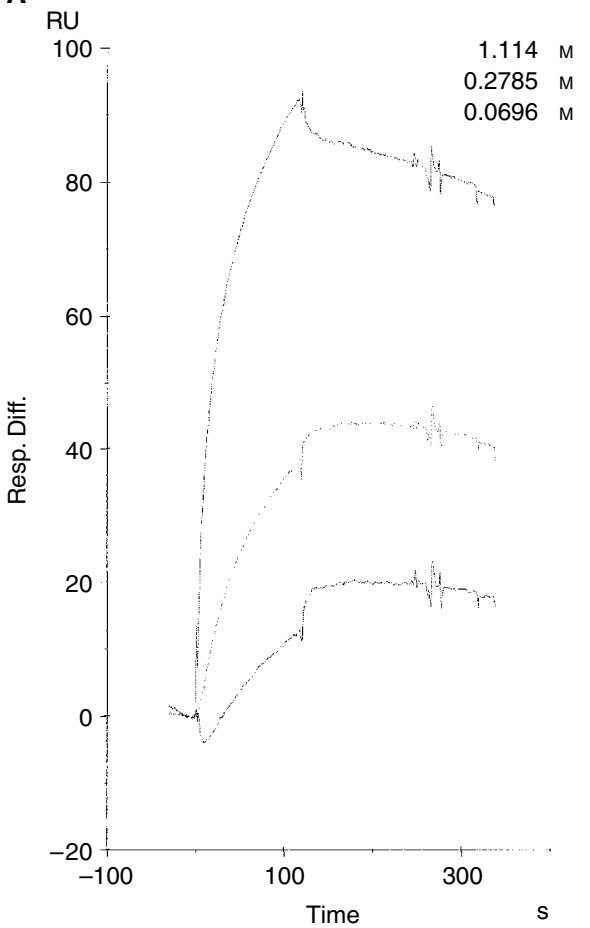

B

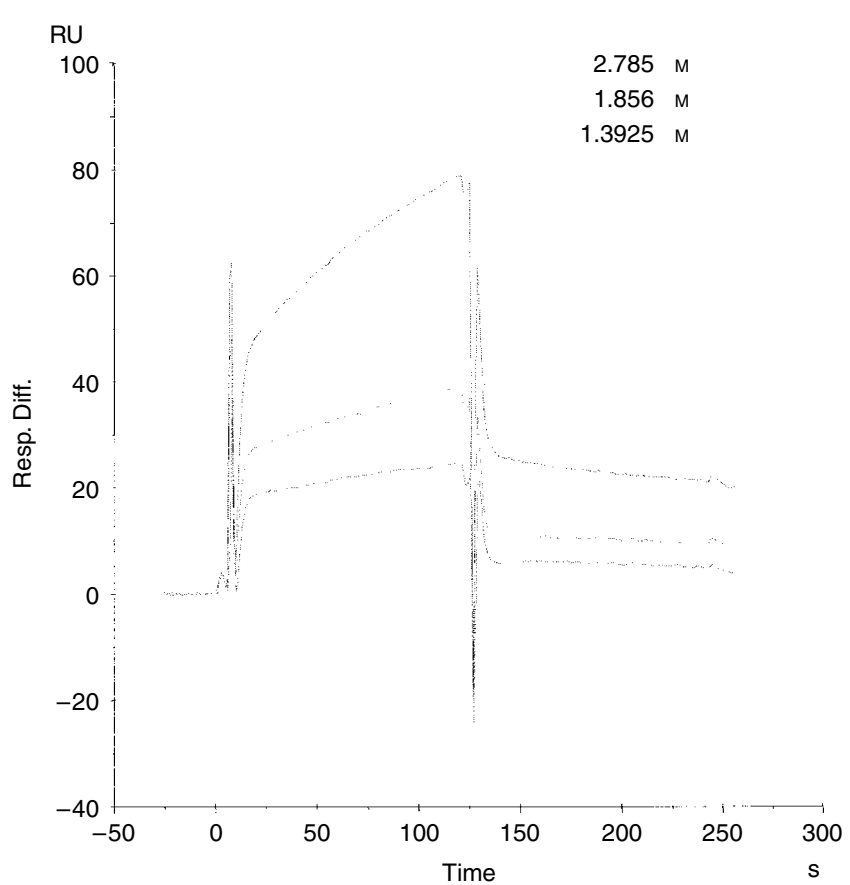

Figure 6 Sensorgrams showing apparent kinetic constants for the binding of SCI 42-reactive antigen to immobilised antigen binding fragments determined in the BIAcore. (A) SCI 42 antibody binding to SCI42-reactive antigen; (B) SCI 42 scFv binding to SCI42-reactive antigen. The surface was regenerated with $30 \mu \mathrm{l}$ of I $\mathrm{M} \mathrm{NaCl}$ in $10 \mathrm{mM}$ glycine $(\mathrm{pH}$ ।.85). The data was evaluated with the I : I Langmuir binding model to estimated the kinetic and binding constants.

\section{A}

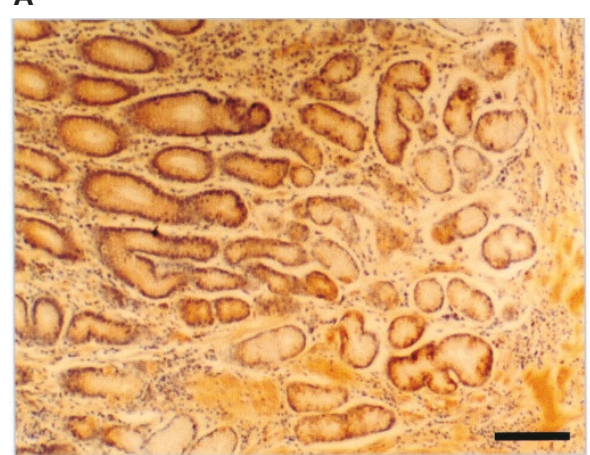

C

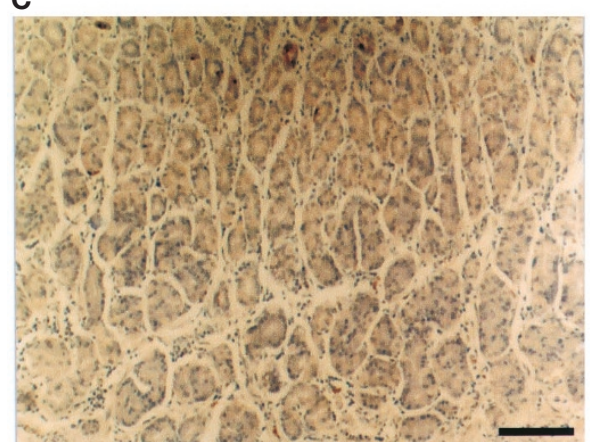

B

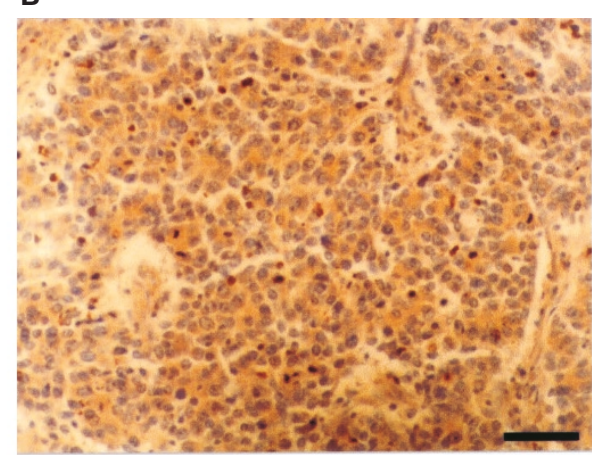

D

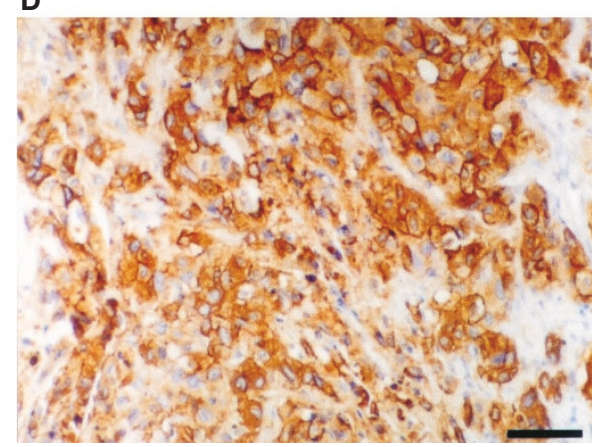

Figure 7 Binding of SCI42 scFv to normal stomach tissue $(\mathbf{C})$ and poorly differentiated human gastric adenocarcinoma tissue (D) as detected by immunohistochemical staining comparable with binding of SCI 42 antibody to normal stomach tissue $(\mathbf{A})$ and poorly differentiated human gastric adenocarcinoma tissue (B). (A) and (C) Scale bar $=60 \mu \mathrm{m} ;(\mathbf{C})$ and (D) Scale bar=30 $\mu \mathrm{m}$. To detect scFv, the system of biotin-labelled SCI $42 \mathrm{scFv}$ and streptavidin/ horseradish peroxidase conjugate was used as this system eliminates nonspecific binding signal because the covalent-like interaction between biotin and streptavidin is so strong that streptavidin is highly specific for biotin. SCI 42 scFv was biotinylated as described in Materials and Methods. 
much faster than that of SC142 scFv and that half life of SC142 antibody-SC142-reactive antigen is theoretically about $16 \mathrm{~h}$. For this reason SC142 scFv binding is inhibited completely by SC142 antibody during competition ELISA.

The $s c F v$ format was chosen for two reasons. First, scFvs are advantageous for the treatment of solid cancers. Because of their small size, these proteins penetrate faster and deeper into tissues and clear more rapidly from the blood than whole IgG or Fabs (Mao et al, 1999). Also, the lack of constant regions mitigates against retention by $\mathrm{Fc}$ receptors found in most tissues and organs, which further reduces their side effects (Yamaguchi et al, 1998). The rapid blood clearance and good tumour penetration of scFvs offer potential advantages over larger antibody molecules for cancer therapy such as radioimmunoguided surgery and antibody-directed enzyme-prodrug therapy (Wels et al, 1992; Mayer et al, 2000). Also, these characteristics of $\mathrm{scFv}$ are applicable to cancer imaging. Cancer imaging requires small, fast penetrating but tightly binding targeting modules, with a rapid plasma clearance. Often $\mathrm{scFv}$ fragments fail on just one parameter, i.e., their off-rate of binding antigen is too fast. This results in insufficient tumour-uptake and poor imaging. Most monoclonal antibodies and also most antibodies from primary phage libraries have typical off-rates that are not better than $10^{-4} \mathrm{~s}^{-1}$ at best. With an off-rate of $10^{-4} \mathrm{~s}^{-1}$, the half life of the antibody-antigen complex is theoretically $1.9 \mathrm{~h}$. A sevenfold improvement, to the $7 \times 10^{-4} \mathrm{~s}^{-1}$ range, would drive to an antigen-antibody half life of $13.3 \mathrm{~h}$. BIAcore assays show that SC142 scFv has an ideal off-rate constant and SC142 scFv could be a good tumour imaging reagent.

\section{REFERENCES}

Bedzyk WD, Weidner KM, Denzin LK, Johnson LS, Hardman KD, Pantoliano MW, Asel ED, Voss Jr EW (1990) Immunological and structural characterization of a high affinity anti-fluorescein single-chain antibody. J Biol Chem 265(30): 18615-18620

Ching CK, Rhodes JM (1990) Purification and characterization of a peanutagglutinin-binding pancreatic-cancer-related serum mucus glycoprotein. Int J Cancer 45(6): 1022-1027

Clark M (2000) Antibody humanization: a case of the 'Emperor's new clothes'. Immunol Today 21(8): 397-402

Correa P (1988) A human model of gastric carcinogenesis. Cancer Res 48: $3554-3560$

Creeth JM, Denborough MA (1970) The use of equilibrium-density-gradient methods for the preparation and characterization of blood-group-specific glycoproteins. Biochem J 117(5): 879-891

Denton G, Sekowski M, Spencer DI, Hughes OD, Murray A, Denley H, Tendler SJ, Price MR (1997) Production and characterization of a recombinant anti-MUC1 scFv reactive with human carcinomas. Br J Cancer 76(5): $614-$ 21

Gruen LC, Kortt AA, Nice E (1993) Determination of relative binding affinity of influenza virus N9 sialidases with the Fab fragment of monoclonal antibody NC41 using biosensor technology. Eur J Biochem 217(1): 319-325

Hewitt HB, Blake ER, Walder AS (1976) A critique of the evidence for active host defence against cancer, based on personal studies of 27 murine tumours of spontaneous origin. Br J Cancer 33(3): 241-259

Hong KM, Jang SJ, Kong G., Song KY, Park JG, Kim DJ, Chung JH, Lee JH, Paik MK, Chung HK (2001) A new tumor-associated antigen of gastrointestinal carcinoma defined by monoclonal antibody SC142. J Cancer Res Clin Oncology 127: $551-558$

Hoogenboom HR, Henderikx P, de Haard H (1998) Creating and engineering human antibodies for immunotherapy. Adv Drug Deliv Rev 31(1-2): $5-31$

Jena PK, Liu AH, Smith DS, Aviszus K, Wysocki LJ (2000) Sequence heterogeneity in Ig kappa transcripts from single B lymphocytes. Mol Immunol 37(6): $265-272$

Lan MS, Finn OJ, Fernsten PD, Metzgar RS (1985) Isolation and properties of a human pancreatic adenocarcinoma-associated antigen, DU-PAN-2. Cancer Res 45(1): $305-310$
Second, because factors likely to influence immunogenicity of therapeutic antibodies are murine constant regions, method of administration, patients' disease status, specificity of antibody, complement activation by antibody, and Fc receptor binding by antibody, scFvs have low immunogenic potential in vivo (Clark, 2000). Despite this advantage, scFvs can not trigger the appropriate human effector systems of complement and Fc receptors in vivo due to the absence of constant regions. To overcome this problem, scFvs can be designed to be more cytotoxic by attaching radioisotopes, cytotoxic drugs or protein drugs in cancer immunotherapy.

In summary, this is the first time a recombinant antibody against SC142-reactive antigen has been developed which is expressed in a high percentage of the cases of gastrointestinal cancer, and retains the ability to bind to tumour cells not normal cells. It may further prove to be a valuable tool in detecting useful markers for gastrointestinal cancer and in enhancing treatment of gastrointestinal cancer.

\section{ACKNOWLEDGEMENTS}

This work was supported by a grant of the Korea Health 21 R\&D Project, Ministry of Health \& Welfare, Republic of Korea (HMP$00-\mathrm{VN}-01-21100-0003)$. We would like to thank Jun-Yeoung Jeon and Hyun-Ick Lee for operating BIAcore biosensor.

Mao S, Gao C, Lo CH, Wirsching P, Wong CH, Janda KD (1999) Phagedisplay library selection of high-affinity human single-chain antibodies to tumor-associated carbohydrate antigens sialyl Lewisx and Lewisx. Proc Natl Acad Sci USA 96(12): 6953-6958

Mayer A, Tsiompanou E, O’Malley D, Boxer GM, Bhatia J, Flynn AA, Chester KA, Davidson BR, Lewis AA, Winslet MC, Dhillon AP, Hilson AJ, Begent RH (2000) Radioimmunoguided surgery in colorectal cancer using a genetically engineered anti-CEA single-chain Fv antibody. Clin Cancer Res 6(5): $1711-1719$

McCafferty J, Griffiths AD, Winter G, Chiswell DJ (1990) Phage antibodies: filamentous phage displaying antibody variable domains. Nature 348(6301): $552-554$

Pantoliano MW, Bird RE, Johnson S, Asel ED, Dodd SW, Wood JF, Hardman KD (1991) Conformational stability, folding, and ligand-binding affinity of single-chain Fv immunoglobulin fragments expressed in Escherichia coli. Biochemistry 30(42): $10117-10125$

Power BE, Caine JM, Burns JE, Shapira DR, Hattarki MK, Tahtis K, Lee FT, Smyth FE, Scott AM, Kortt AA, Hudson PJ (2001) Construction, expression and characterisation of a single-chain diabody derived from a humanised anti-Lewis Y cancer targeting antibody using a heat-inducible bacterial secretion vector. Cancer Immunol Immunother 50(5): 241 - 250

Sambrook J, Fritsch EF, Maniatis T (1989) Molecular Cloning: a Laboratory Manual. 2nd edn. Cold Spring Harbor, New York: Cold Spring Harbor Press

Tsumoto K, Shinoki K, Kondo H, Uchikawa M, Juji T, Kumagai I (1998) Highly efficient recovery of functional single-chain Fv fragments from inclusion bodies overexpressed in Escherichia coli by controlled introduction of oxidizing reagent-application to a human single-chain Fv fragment. J Immunol Methods 219(1-2): 119-129

Verma M, Davidson EA (1994) Mucin genes: structure, expression and regulation. Glycoconj J 11: $172-179$

Wels W, Harwerth IM, Mueller M, Groner B, Hynes NE (1992) Selective inhibition of tumor cell growth by a recombinant single-chain antibody-toxin specific for the erbB-2 receptor. Cancer Res 52(22): 6310-6317 
Winter G, Milstein C (1991) Man made antibodies. Nature 349: 293-299 Yamaguchi A, Ding K, Maehara M, Goi T, Nakagawara G (1998) Expression of $\mathrm{nm} 23-\mathrm{H} 1$ gene and Sialyl Lewis X antigen in breast cancer. Oncology 55(4): $357-362$
Yi K, Chung J, Kim H, Kim I, Jung H, Kim J, Choi I, Suh P, Chung H (1999) Expression and characterization of anti-NCA-95 scFv (CEA $79 \mathrm{scFv}$ ) in a prokaryotic expression vector modified to contain a $S f i \mathrm{I}$ and NotI site. Hybridoma 18(3): 243-249 